\title{
Purchase Behaviour Determinants on Online Mobile Game in Indonesia
}

\author{
M. Rezky Akbar*; Gugus Irianto; Ainur Rofiq \\ Faculty of Economics and Business, University of Brawijaya, Indonesia \\ Email: rezkyakbar93@gmail.com
}

http://dx.doi.org/10.18415/ijmmu.v5i6.457

\begin{abstract}
This study aimed to examine the determinants of purchase behaviour in online mobile game. This study was conducted based on the Unified Theory of Acceptance and Use of Technology second version (UTAUT2) with additional customization and advancement. Partial Least Square Structural Equation Model (SEM-PLS) was applied to examine this research model. The samples were collected using online surveys to the users of Mobile Legends: Bang Bang, and then there were 457 respondents obtained. The result of this study revealed that performance expectancy, payment ability, hedonic motivation, price value, habit, customization and advancement had a positive effect on purchase intention, and the intention also had a positive effect on actual purchase. However, it was found that effort expectancy and social influence did not significant on purchase intention. The result of this study can be used as a reference for game develovers so that in-game purchases can be accepted by users.
\end{abstract}

Keywords: UTAUT2; Customization; Advancement; Purchase Behaviour; Online Mobile Game; Mobile Legends: Bang Bang

\section{Introduction}

Mobile games are gaining in popularity with the increasing number of the users. Based on the survey results of the SuperData Research and Unity Technology (2017) in the report of 2016 Mobile Games and VR Year in Review, the mobile game market in the world had generated the revenue of \$40.6 billion in 2016. The revenue was earned by virtue of high increase in users who pay for the games. In the report, they also stated that Indonesia has a large market potential. This is inasmuch as the number of game application installations by Indonesian users is three times higher compared to that of three other countries such as the United States, Mexico and India. In addition, the average income earned from each user in Indonesia has a growth rate of $7 \%$ which is almost like that of India. Based on the data, the percentage of mobile game consumers who pay in Indonesia is almost 50\% higher than that of India, and Indonesian users tend to buy twice as much.

There are three models of business generally applied by the game developers to earn income. They are comprised of pay-per-download model, in-game advertisement sponsorship model, and in-game sale model (Han \& Windsor., 2013). In-game sale model is the most promising for mobile games. The implementation of business strategy through in-game sale model is undertaken by providing the premium 
virtual items in the games. Nevertheless, some game developers still face a dilemma when the users are free to use the games but refuse to make purchases in them (Han \& Windsor., 2013). Guo \& Barnes (2011) explain that virtual item transaction system is seen as technology, and they measure the interest in using the transaction system. This means that when the users refuse to make purchases in the games, as the consequence, the users will also refuse to adopt the transaction system applied in the games.

Purchasing behavior in online mobile games plays an important role when the games do not take the fee of access for the users to play them (Mäntymäki \& Salo., 2013). As to replace it, the game developers need to implement a purchase system in the game to earn income. One of the most popular and favorite free games in Google Play among the regions of Indonesia is Mobile Legends: Bang Bang with a total of 8 million users per day (KumparanTECH., 2017), and the generated revenue reaches \$ 5.3 million in 2017 (Lopez., 2017). The revenue is derived from the exchange of virtual currencies referring to Diamond and virtual items so-called Skins, as well as the premium members with an exclusive feature so-called Starlight Member.

A couple of previous studies in the context of virtual item purchases have explained the factors motivating the users to be interested in making purchases (Hsu \& Lu., 2007; Lehdovirta., 2009; Guo \& Barnes., 2011; Guo \& Barnes., 2012; Mäntymäki \& Salo., 2013; Han \& Windsor., 2013; Hamari., 2015). A series of studies conducted by Guo \& Barnes $(2007 ; 2009 ; 2011 ; 2012)$ have addressed the problems of buying behavior in online games. However, the studies on purchasing behavior in online mobile games are still limited. This is due to, among previous studies, merely focusing on the games on PC devices, while the studies on smartphone devices are still not adequate.

To answer behavioral problems in online mobile games, this study uses UTAUT2 (Venkatesh., et al., 2012) as the basic model. The researcher also adds the construct of customization and advancement adopted from Yee $(2006)$ and Guo \& Barnes $(2011 ; 2012)$ because the construct is associated with the users' basic motivation to improve their gaming experience and progress which are then used to complement the motivational factors in UTAUT2 game context.

\section{Literatur Review and Study Hypotheses}

Performance expectancy can be defined as the level of users' confidence whereby using technology can increase their productivity (Venkatesh., et al, 2003). In this case, when individuals believe that using technology is able to improve something they want to achieve, it will shape their interest in using technology. Guo \& Barnes (2011) explained that the construct of performance expectancy plays a role as one of the main beliefs pertinent to the interest in using technology to buy virtual items. Guo \& Barnes's study $(2012$; 2011) found that performance expectancy had a positive effect on purchase intention to buy virtual items. The study conducted by Mäntymäki \& Salo (2013) also found that the perceived usefulness had a positive effect on purchase intention. In this case, it can be drawn a conclusion that in order to improve the users' performance and experience in playing Mobile Legends: Bang Bang, the users will be triggered and interested in making purchases in the game.

$\mathbf{H}_{1}$ : Performance expectancy has an effect on the purchase intention in online mobile games.

Effort expectancy is defined as the level of the users' confidence in that a technology is easy to use (Venkatesh., et al., 2003). Individuals who have already understood a technology tend to suppose that the technology can be easily used so that it triggers their interest. Venkatesh., et al. $(2003 ; 2012)$ prove that effort expectancy affects behavioral interests in both organizational and individual contexts. Besides, Guo \& Barnes (2011; 2012), and Mäntymäki \& Salo (2013) have empirically attested to the effect of effort expectancy on purchase intention in online games. Effort expectancy is an important factor that helps explain the merits of using technology, so that it can influence the users to choose their adopted 
technology when they consider making a purchase. In so doing, the users will choose which technology is more suitable and easier to use.

$\mathbf{H}_{2}$ : Effort expectancy has an effect on the purchase intention in online mobile games.

Social influence is defined as the level to what extent the users believe that other people think that they must use technology (Venkatesh., et al 2003). This refers to an impulse formed by the people around the users. As explained in the study conducted by Venkatesh, et al. (2003), the social influence per se will be significant when used under the condition of a mandatory use. However, this case is in contrast to Venkatesh, et al. (2012) who find that social influence has an effect on the customers' use context. Basically, buying virtual items in the online mobile games is voluntary, and smartphone usage is also very individual. However, the great number of users in online mobile games causes the increasing growth of social interaction in the games (Mäntymäki \& Salo., 2013). Thus, social influence will make the users interested in buying virtual items in the online mobile games to increase their social status.

$\mathbf{H}_{3}$ : Social influence has an effect on the purchase intention in online mobile games.

Since the purchase made in the online mobile games provides a number of ways for electronic payments such as by transferring via ATM or mobile banking, using credit cards, e-money and credit for cellular operators, or using the other service provider such as minimarket, it can be assumed that making purchases in the games has an easy process of payment that can be made by the users. In other words, the users can choose the payment method and technology that suit their capabilities. Payment ability can be defined as the level of someone's capability whereby the available payment media supports him to make a purchase. Payment ability is a reconstruction based on the construct of facilitating condition (Venkatesh., et al., 2003). Payment ability focuses on a person's ability to make payments (both for a technology use or the purchase of goods and services) through the payment method and the technology which are provided. Accordingly, when a user has confidence in his ability to make a suitable payment, then it is possible that he will make a purchase in an online mobile game.

$\mathbf{H}_{4}$ : Payment ability has an effect on the purchase intention in online mobile games.

Hedonic motivation is defined as pleasure derived from the use of technology (Venkatesh., et al., 2012). Some prior studies measure the construct of hedonic motivation with the term so-called enjoyment or playfulness (Guo \& Barnes., 2011, 2012; Mäntymäki \& Salo., 2013; Han \& Windsor., 2013). The results of the study conducted by Mäntymäki \& Salo (2013) and Han \& Windsor (2013) prove that hedonic motivation has an effect on purchase intention in the online mobile games.

H$_{5}$ : Hedonic motivation has an effect on the purchase intention in online mobile games.

Price value is defined as the exchange between the perceived benefits and the costs of obtaining the use of a technology (Venkatesh., et al., 2013). Venkatesh, et al. (2013) explained that when using a technology is perceived to have greater benefits compared to the costs of obtaining it, it will trigger the users to adopt it. In that study, it was found that the price factor had an effect on the interest in using technology. Guo \& Barnes (2011) test the perceived value for the interest in purchasing virtual items. The test results in the presence of a significant influence on buying interest. Guo \& Barnes (2011) explain that the more appropriate the perceived cost will result in high perceived value. The same result is also found in the study conducted by Guo \& Barnes (2012) whereby the perceived value affects the interest in buying virtual items. Since virtual items have a price charged to the users, they will certainly consider buying the virtual items with the question whether the benefits obtained are commensurate with the price paid. This of course goes back to the game users' purpose whether they will get more experiences such as fun or gaming performance when playing online games using the virtual items.

$\mathbf{H}_{6}$ : Price value has an effect on the purchase intention in online mobile games.

Habit is defined as the extent to which someone does something automatically (Venkatesh., et al., 2013). Venkatesh, et al. (2013) found that habit had an influence on the interest in using the system. 
According to them, habit occurs because someone has an experience. For example, in an organization, someone who has used technology for three months will change his behavior. Guo \& Barnes (2011) test the habit for buying behavior in online games. They found that habit had a positive effect on the behavior of buying virtual items. Guo \& Barnes (2011) explain that every user is unlikely to never use the purchase technology that is available in the online game even though it is only to buy some free virtual items. Then, the users' habit will lead them to get the paid virtual items as a result of the frequency of using the purchase system in the game. This habit will bring them to make a purchase in order to obtain a goal to improve their experience in the game. Therefore, the researcher considers whether the users' habits in making a purchase in the game, even if it is for free virtual items, will bring them to be interested in making a purchase for paid virtual items. In line with Venkatesh, et al. (2012), the users who have had a habit of using certain technologies make possible to create a positive attitude and interest in using them.

$\mathbf{H}_{7}$ : Habit has an effect on the purchase intention in online mobile games.

The construct of customization and advancement was first tested by Guo \& Barnes (2011; 2012). Customization refers to the extent to which an individual's desire to obtain a suitable appearance in the character of the game, and advancement refers to the extent to which a person wants to obtain an improvement in the used character (Yee., 2006). This also relates to his attitude to look at these two things. Wohn \& $\mathrm{Na}$ (2012) in his meta-analysis found that an attitude had the most powerful influence on buying interest in online games. In other words, when a user responds that customizing and increasing ability of the characters in the game is perceived to have positive benefits, it will increase his interest in buying the items capably making a good improvement of the characters.

H8: Customization has an effect on the purchase intention in online mobile games.

$\mathbf{H}_{9}$ : Advancement has an effect on the purchase intention in online mobile games.

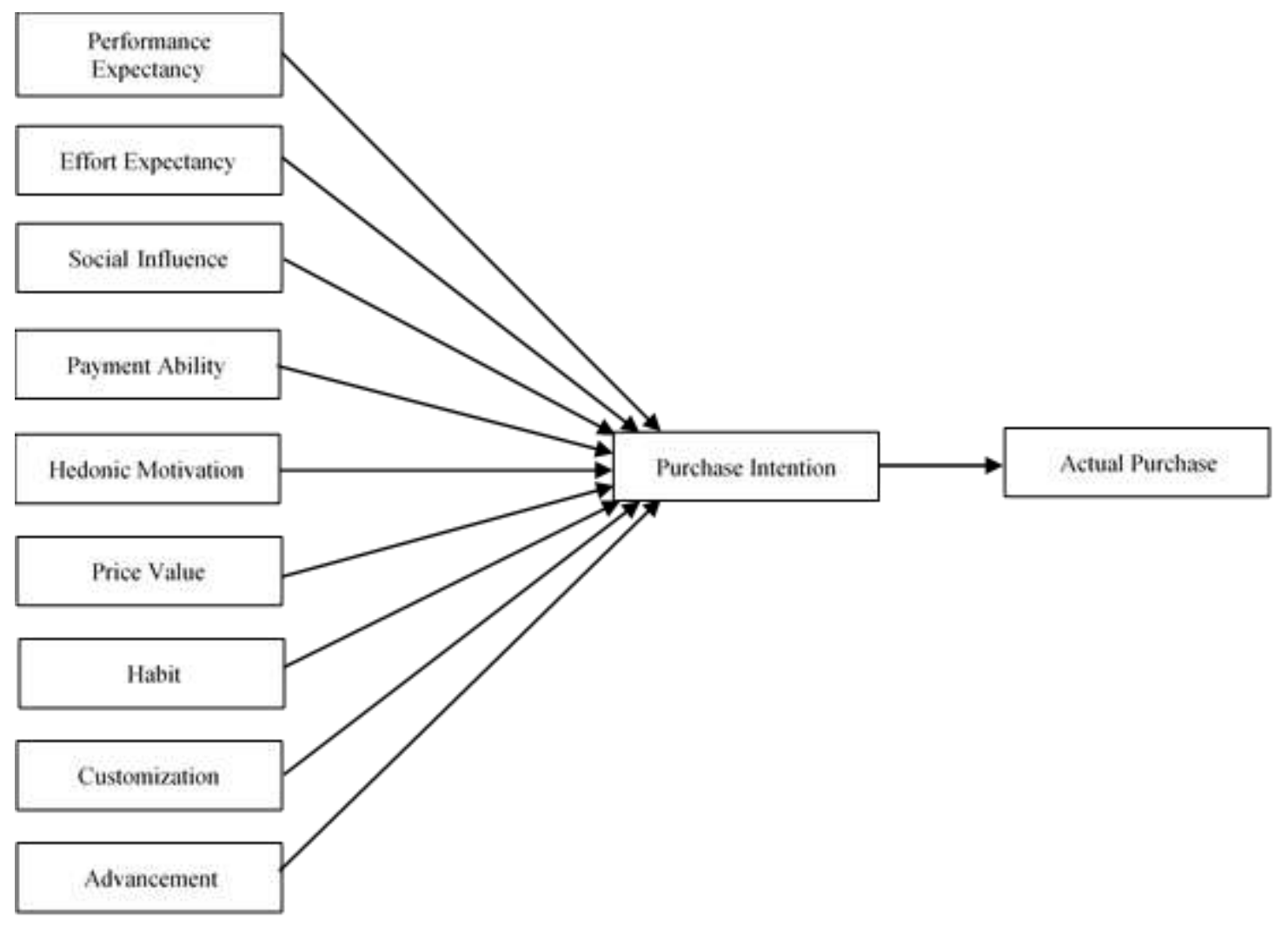

Fig. 1 Research Model 
Actual purchase is a concrete action taken by someone to make a purchase in an online mobile game. According to Ajzen (1991), an individual's real behavior is carried out because the individual has a desire to do something (behavior intention). In other words, an actual purchase occurs because there is someone's interest in buying (purchase intention). The influence of behavioral interest on usage behavior is seen in the UTAUT model (Venkatesh., et al., 2003) and UTAUT 2 (Venkatesh., et al., 2012). The result shows that behavioral interest influences the usage behavior in the context of technology acceptance. In the context of making purchases in online games, Guo \& Barnes $(2011 ; 2012)$ examine the effect of purchase intention on the actual purchase. That study finds out that the actual purchase is influenced by the purchase intention.

$\mathbf{H}_{10}$ : Purchase intention has a positive effect on the actual purchase in online mobile games.

\section{Methodology}

\subsection{Population and Sample}

This study used a survey method. The population of this study included all the online game users of Mobile Legends: Bang Bang in Indonesia. Mobile Legends: Bang Bang was chosen as the object of this study because this application referred to the most popular online mobile game and as the best-selling game on the Google Play Store for the regions of Indonesia. Convenience sampling method was applied to select the samples of this study. The respondents targeted were those who used the game application of Mobile Legends: Bang Bang and had made purchases in the game.

\subsection{Data Collection and Sample Characteristics}

The data collection was carried out by distributing questionnaires via online using Google Form, and they were disseminated through social media such as Facebook, Instragram and Whatsapp. The number of responses received reached as many as 606 respondents. However, 61 respondents who returned the questionnaires gave inconsistent answers in the questionnaires, and 88 respondents were not in accor\&ce with the criteria assigned in this study. Therefore, they had to be excluded.

The questionnaires that could be processed for this study were those returned by 457 samples. The samples in this study were dominated by men (91.47\%). Most of the samples were in the range of 1020 years $(54.27 \%)$, followed in the range of 21-30 years $(45.08 \%)$. Then, many of the samples were students $(69.80 \%)$, followed by samples working as employees (21.01). In addition, most samples had used the game application for more than a year (69.80\%), and the duration of use in a day could reach three to five hours $(49.45 \%)$.

\section{Evaluation of Measurement Model}

This study adopted several measurement items derived from Venkatesh, et al. (2012) and Guo \& Barnes (2011). A total of 37 items were used in this study, and each item was measured using seven likert scales which began from strongly disagree to strongly agree. The pilot test was conducted using 30 samples referring to the users of Mobile Legends: Bang Bang to improve the suitability of the instrument. The pilot test result manifested that the instrument was valid and reliable for use in this study.

This study used the method of Structural Equation Model (SEM) with the analysis technique of Partial Least Square Structural Equation Model (SEM-PLS) through SmartPLS 3.0 software. SEM-PLS was used because the analysis did not require the assumption of data normality, and the result remained 
robust even though there were found some missing data, abnormal data distribution, and a small sample size.

Table 1 Loading factor and cross loading

\begin{tabular}{|c|c|c|c|c|c|c|c|c|c|c|c|}
\hline & PE & $\mathrm{EE}$ & SI & PA & HM & PV & HB & CT & $\mathrm{AD}$ & PI & $\mathrm{AP}$ \\
\hline PE1 & 0.862 & 0.325 & 0.215 & 0.407 & -0.290 & 0.056 & 0.437 & 0.133 & 0.400 & 0.508 & 0.401 \\
\hline PE2 & 0.765 & 0.277 & 0.137 & 0.356 & -0.261 & 0.059 & 0.322 & 0.043 & 0.294 & 0.332 & 0.279 \\
\hline PE3 & 0.734 & 0.241 & 0.209 & 0.283 & -0.354 & 0.111 & 0.392 & 0.048 & 0.316 & 0.348 & 0.320 \\
\hline EE1 & 0.304 & 0.896 & -0.047 & 0.445 & -0.273 & 0.001 & 0.155 & 0.025 & 0.154 & 0.163 & 0.183 \\
\hline EE2 & 0.301 & 0.940 & -0.088 & 0.450 & -0.283 & -0.005 & 0.149 & 0.018 & 0.187 & 0.182 & 0.217 \\
\hline EE3 & 0.332 & 0.895 & -0.082 & 0.467 & -0.244 & 0.024 & 0.150 & 0.013 & 0.173 & 0.157 & 0.208 \\
\hline EE4 & 0.330 & 0.811 & 0.039 & 0.481 & -0.326 & 0.016 & 0.297 & 0.017 & 0.243 & 0.219 & 0.347 \\
\hline SI1 & 0.287 & 0.068 & 0.873 & 0.200 & -0.131 & -0.027 & 0.296 & 0.032 & 0.323 & 0.304 & 0.132 \\
\hline SI2 & 0.108 & -0.139 & 0.734 & 0.025 & -0.088 & 0.015 & 0.142 & -0.060 & 0.122 & 0.124 & 0.035 \\
\hline SI3 & 0.100 & -0.146 & 0.783 & 0.013 & 0.030 & 0.035 & 0.188 & -0.006 & 0.148 & 0.170 & 0.048 \\
\hline PA1 & 0.369 & 0.349 & 0.122 & 0.820 & -0.212 & -0.017 & 0.301 & 0.084 & 0.186 & 0.328 & 0.311 \\
\hline PA2 & 0.423 & 0.512 & 0.046 & 0.827 & -0.313 & 0.039 & 0.251 & 0.119 & 0.234 & 0.292 & 0.312 \\
\hline PA3 & 0.365 & 0.481 & 0.061 & 0.853 & -0.265 & -0.006 & 0.279 & 0.106 & 0.199 & 0.292 & 0.336 \\
\hline PA4 & 0.121 & 0.181 & 0.221 & 0.409 & -0.119 & 0.112 & 0.091 & 0.057 & 0.130 & 0.188 & 0.036 \\
\hline HM1 & -0.354 & -0.295 & -0.074 & -0.265 & 0.931 & -0.001 & -0.248 & 0.062 & -0.210 & -0.166 & -0.317 \\
\hline HM2 & -0.349 & -0.298 & -0.055 & -0.300 & 0.956 & 0.016 & -0.231 & 0.052 & -0.217 & -0.160 & -0.281 \\
\hline HM3 & -0.363 & -0.322 & -0.129 & -0.316 & 0.943 & -0.009 & -0.262 & 0.046 & -0.227 & -0.182 & -0.303 \\
\hline PV1 & 0.060 & -0.015 & 0.024 & -0.001 & 0.031 & 0.949 & 0.058 & 0.078 & 0.047 & 0.150 & -0.025 \\
\hline PV2 & 0.110 & 0.028 & 0.020 & 0.054 & -0.012 & 0.966 & 0.087 & 0.062 & 0.026 & 0.137 & -0.021 \\
\hline PV3 & 0.095 & 0.020 & -0.059 & 0.037 & -0.021 & 0.931 & 0.061 & 0.062 & 0.017 & 0.114 & 0.009 \\
\hline HB1 & 0.450 & 0.223 & 0.246 & 0.291 & -0.254 & 0.055 & 0.912 & 0.142 & 0.475 & 0.648 & 0.484 \\
\hline HB2 & 0.395 & 0.138 & 0.268 & 0.247 & -0.226 & 0.060 & 0.905 & 0.103 & 0.484 & 0.609 & 0.429 \\
\hline HB3 & 0.430 & 0.162 & 0.299 & 0.272 & -0.162 & 0.054 & 0.888 & 0.111 & 0.556 & 0.659 & 0.354 \\
\hline HB4 & 0.479 & 0.267 & 0.206 & 0.345 & -0.299 & 0.090 & 0.871 & 0.095 & 0.488 & 0.647 & 0.463 \\
\hline CT1 & 0.095 & 0.018 & 0.006 & 0.107 & 0.045 & 0.058 & 0.146 & 0.875 & 0.128 & 0.239 & 0.010 \\
\hline CT2 & 0.121 & 0.061 & 0.018 & 0.160 & 0.051 & 0.072 & 0.117 & 0.888 & 0.099 & 0.184 & 0.081 \\
\hline CT3 & 0.079 & 0.017 & -0.012 & 0.109 & 0.055 & 0.056 & 0.112 & 0.940 & 0.122 & 0.215 & 0.017 \\
\hline CT4 & 0.083 & -0.020 & -0.001 & 0.078 & 0.054 & 0.077 & 0.074 & 0.925 & 0.086 & 0.192 & -0.034 \\
\hline AD1 & 0.273 & 0.193 & 0.111 & 0.216 & -0.228 & -0.042 & 0.196 & 0.073 & 0.485 & 0.199 & 0.164 \\
\hline $\mathrm{AD} 2$ & 0.407 & 0.248 & 0.195 & 0.258 & -0.285 & 0.029 & 0.538 & 0.081 & 0.814 & 0.558 & 0.333 \\
\hline AD3 & 0.355 & 0.114 & 0.282 & 0.195 & -0.102 & 0.029 & 0.490 & 0.152 & 0.866 & 0.624 & 0.239 \\
\hline AD4 & 0.277 & 0.154 & 0.228 & 0.130 & -0.148 & 0.048 & 0.370 & 0.049 & 0.790 & 0.458 & 0.229 \\
\hline PI1 & 0.526 & 0.215 & 0.223 & 0.370 & -0.198 & 0.133 & 0.678 & 0.239 & 0.598 & 0.924 & 0.365 \\
\hline PI2 & 0.486 & 0.215 & 0.258 & 0.366 & -0.173 & 0.148 & 0.687 & 0.233 & 0.632 & 0.951 & 0.352 \\
\hline PI3 & 0.428 & 0.147 & 0.304 & 0.308 & -0.130 & 0.115 & 0.636 & 0.171 & 0.597 & 0.919 & 0.301 \\
\hline AP1 & 0.400 & 0.253 & 0.094 & 0.307 & -0.276 & -0.025 & 0.483 & -0.008 & 0.335 & 0.373 & 0.932 \\
\hline AP2 & 0.375 & 0.253 & 0.102 & 0.344 & -0.306 & 0.002 & 0.375 & 0.052 & 0.238 & 0.272 & 0.868 \\
\hline
\end{tabular}

Both convergent and discriminant validity tests were used to assess the validity of the model. Convergent validity had two parameters, loading factor and average variance extract (AVE) (Abdillah \& Hartono., 2015). Most factor loading values for each indicator were more than 0.7 as shown in Table 1. However, there were two indicators whose values were less than 0.7 , namely the PA4 indicator and the 
AD1 indicator. In Table 2, the AVE value for each construct was more than 0.5. This condition meant that the AVE value had met the requirement of convergent validity. This result also strengthened the reason that the indicators having a loading factor of more than 0.4 to less 0.7 did not need to be excluded because the AVE value was still above the value limit (Sholihin and Ratmono., 2013).

Table 2 Average Variance Extract (AVE)

\begin{tabular}{lc}
\hline Constructs & AVE \\
\hline Performance Expectancy & 0.622 \\
Effort Expectancy & 0.787 \\
Social Influence & 0.638 \\
Payment Ability & 0.563 \\
Hedonic Motivation & 0.890 \\
Price Value & 0.900 \\
Habit & 0.800 \\
Customization & 0.823 \\
Advancement & 0.568 \\
Purchase Intention & 0.868 \\
Actual Purchase & 0.811 \\
\hline
\end{tabular}

The next step was to test the discriminant validity. The parameters used in this test were by looking at the value of cross loading and comparing the roots of AVE with other construct correlations. Table 1 shows a good cross loading because each indicator in its construct exceeds its correlation. Table 4 also shows that the root value of AVE exceeds the correlation. Thus, it can be concluded that the measurement model in this study is valid.

Table 3 Square roots of AVE

\begin{tabular}{llllllllllll}
\hline \multicolumn{2}{l}{ PE } & EE & SI & PA & HM & PV & HB & CT & AD & PI & AP \\
\hline PE & $\mathbf{0 . 7 8 9}$ & & & & & & & & & & \\
EE & 0.360 & $\mathbf{0 . 8 8 7}$ & & & & & & & & & \\
SI & 0.240 & -0.044 & $\mathbf{0 . 7 9 9}$ & & & & & & & & \\
PA & 0.447 & 0.524 & 0.135 & $\mathbf{0 . 7 5 0}$ & & & & & & & \\
HM & -0.377 & -0.324 & -0.093 & -0.312 & $\mathbf{0 . 9 4 4}$ & & & & & & \\
PV & 0.092 & 0.010 & -0.001 & 0.030 & 0.002 & $\mathbf{0 . 9 4 9}$ & & & & & \\
HB & 0.491 & 0.222 & 0.285 & 0.324 & -0.263 & 0.072 & $\mathbf{0 . 8 9 4}$ & & & & \\
CT & 0.104 & 0.020 & 0.003 & 0.124 & 0.056 & 0.071 & 0.126 & $\mathbf{0 . 9 0 7}$ & & & \\
AD & 0.434 & 0.220 & 0.283 & 0.253 & -0.231 & 0.033 & 0.561 & 0.122 & $\mathbf{0 . 7 5 3}$ & & \\
PI & 0.517 & 0.208 & 0.280 & 0.375 & -0.180 & 0.142 & 0.717 & 0.231 & 0.654 & $\mathbf{0 . 9 3 1}$ & \\
AP & 0.431 & 0.280 & 0.107 & 0.357 & -0.319 & -0.015 & 0.483 & 0.019 & 0.325 & 0.365 & $\mathbf{0 . 9 0 0}$ \\
\hline
\end{tabular}

Reliability testing used Cronbach's alpha value parameter and composite reliability. Based on Table 5, it can be seen that each construct in this study has a Cronbach's alpha value and a composite reliability of more than 0.7 . 
Tabel 4 Cronbach's Apha \& composite reliability

\begin{tabular}{lcc}
\hline Constructs & Cronbach's Alpha & Composite Reliability \\
\hline Performance Expectancy & 0.702 & 0.831 \\
Effort Expectancy & 0.910 & 0.936 \\
Social Influence & 0.749 & 0.840 \\
Payment Ability & 0.712 & 0.829 \\
Hedonic Motivation & 0.938 & 0.961 \\
Price Value & 0.945 & 0.964 \\
Habit & 0.916 & 0.941 \\
Customization & 0.929 & 0.949 \\
Advancement & 0.746 & 0.835 \\
Purchase Intention & 0.924 & 0.952 \\
Actual Purchase & 0.772 & 0.895 \\
\hline
\end{tabular}

\section{Structural Model Evaluation}

Structural model evaluation aims at seeing how well the model is able to explain the endogenous construct and seeing the results of hypothesis testing. The structural model is examined through two parameters, namely R2 (R-square) and path coefficient.

Testing the hypothesis in this study used two-tailed testing at $5 \%$ alpha. Based on Table 7, it is shown that $\mathrm{H} 1, \mathrm{H} 4, \mathrm{H} 5, \mathrm{H} 6, \mathrm{H} 7, \mathrm{H} 8, \mathrm{H} 9$ and $\mathrm{H} 10$ are declared acceptable because they are significantly less than $5 \%$. The value of $\beta$ shows a positive coefficient of each accepted hypothesis. However, $\mathrm{H} 2$ and $\mathrm{H} 3$ are declared rejected.

Table $5 \mathrm{R}^{2}$ values

\begin{tabular}{lc}
\hline Konstruk & $\mathrm{R}^{2}$ \\
\hline Purchase Intention & 0.6573 \\
Actual Purchase & 0.1334 \\
\hline
\end{tabular}

Table 6 depicts that performance expectancy, effort expectancy, social influence, payment ability, hedonic motivation, price value, habit, customization, and advancement are able to explain the change in variance towards the construct of purchase intention with a value of R2 0.6573 . Then, the construct of purchase intention can explain the change in variance towards the actual purchase by 0.1334 . This means that there are still other remaining constructs which can explain change in variance outside of the proposed model. 
Table 6 Path coefficient

\begin{tabular}{llcrrr}
\hline Hypothesis & Construct & $\beta$ & t-statistic & P value & Decisions \\
\hline H1 & PE -> PI & 0.128 & 3.623 & 0.000 & Accepted \\
H2 & EE -> PI & -0.050 & 1.445 & 0.149 & Rejected \\
H3 & SI -> PI & 0.019 & 0.583 & 0.560 & Rejected \\
H4 & PA -> PI & 0.126 & 3.008 & 0.003 & Accepted \\
H5 & HM -> PI & 0.079 & 2.835 & 0.005 & Accepted \\
H6 & PV -> PI & 0.078 & 2.813 & 0.005 & Accepted \\
H7 & HB -> PI & 0.436 & 9.316 & 0.000 & Accepted \\
H8 & CT -> PI & 0.098 & 3.525 & 0.000 & Accepted \\
H9 & AD -> PI & 0.331 & 8.155 & 0.000 & Accepted \\
H10 & PI -> AP & 0.365 & 9.149 & 0.000 & Accepted \\
\hline
\end{tabular}

\section{Discussion and Conclusion}

The result of hypothesis testing in this study indicated that UTAUT2 had a role to predict the model of buying behavior in online mobile games in Indonesia. This showed that performance expectancy, payment ability, hedonic motivation, price value and habit had a positive effect on the purchase intention in online mobile games. Then, customization and advancement also had a positive effect on the purchase intention. Overall, this result indicated that the research model was able to explain $65.73 \%$ of the variance in the purchase intention.

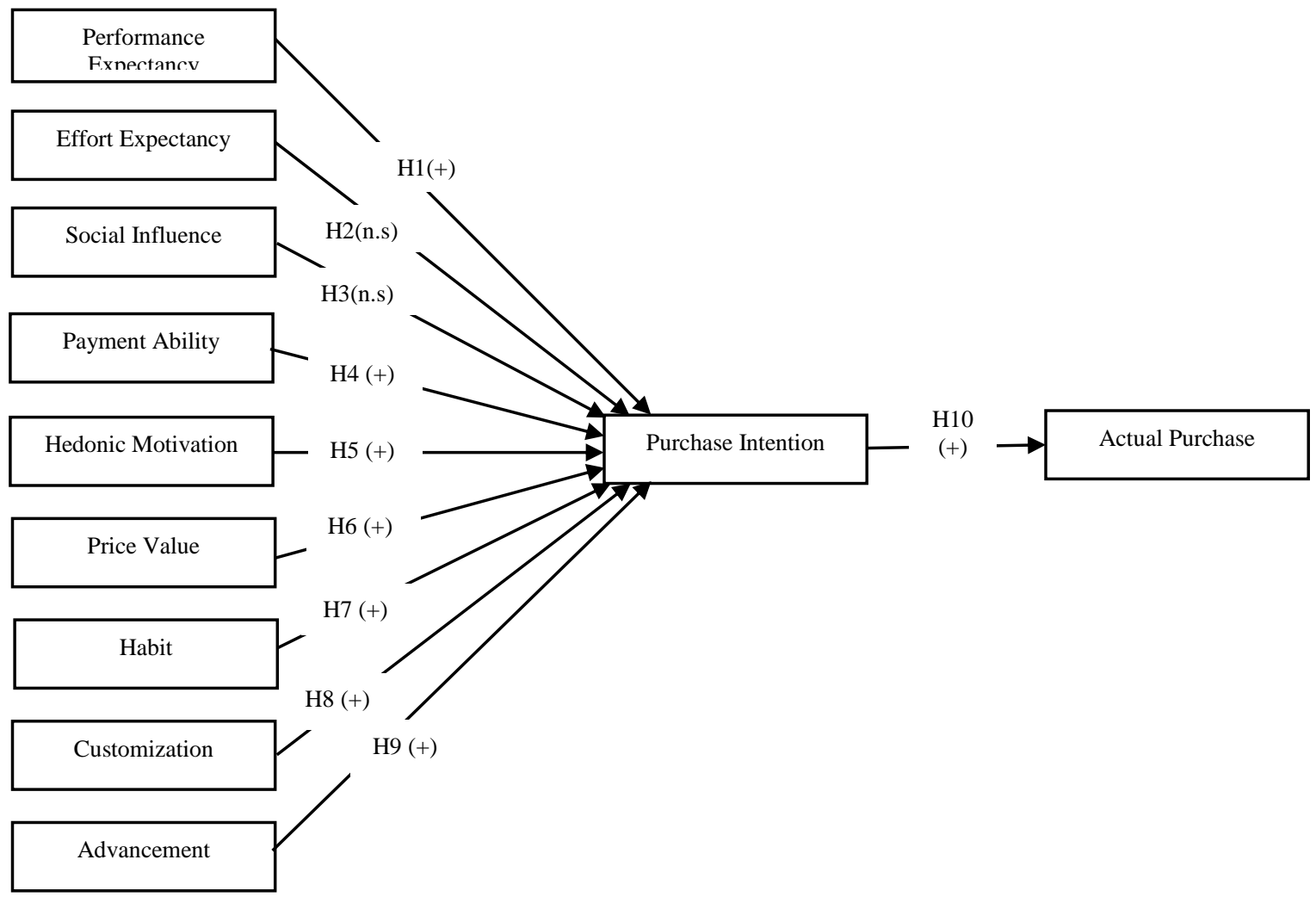

Fig 2 Research model of hypothesis testing 
Habit becomes the strongest determinant that influences purchase intention and then followed by advancement. This shows that the more accustomed the users interact with the purchase in the game, the higher their interest in making purchases in the game. The users also tend to choose to make purchases if virtual items can provide them with useful progress used in the game. This study also provides evidence that the reconstruction of payment abilities has a positive effect on purchase intention in an online mobile game. Since the condition that facilitates to make payment for every purchase in an online mobile game is available, this can encourage the users to be willing to do so. In other words, the higher the availability of resources and the support of payment media in an online mobile game, the higher the users' intention in making purchases in an online mobile game.

This study find no significant effect of effort expectancy and social influence on the purchase intention. The reason for the cause of effort expectancy which had no significant was because it was possibly related to the characteristics of respondents dominated by young users who had basically been accustomed to use the systems on the internet (Moro\& and DeFrenco (2016). They no longer saw that the use of a system required an effort. Therefore, they ignored the ease of making purchases in an online mobile game. In addition, the reason of social influence had no significant on the purchase intention because the purchase made in an online mobile game was not a necessity for the users. On the other hand, the smartphone users also had a high personality so that a sort of social influence did not affect them to be interested in making a purchase (Guo \& Barnes., 2011; 2012; Martin and Herrero., 2012).

The result of this study also found a strong influence of purchase intention on the actual purchase. This condition proved that buying interest was the main driver for the users in the context of purchase behavior in an online mobile game. The higher the users' intention in making a purchase in an online mobile game, the higher the actual action would occur.

This study serves two implications in both theoretical and practical aspects. The findings of this study have empirically stated that UTAUT2 is able to explain the behavior problems in an online mobile game in Indonesia. In addition, customization and advancement also have a good role to predict the intention of the users' behavior in the game. This study can be used as a reference for game developers to develop a game and to improve the quality of experience in the game so that making purchases in the game can be accepted by the users. Supports can also be given to e-commerce that provides the media purchases in the online game which are acceptable for the users.

A number of limitations in this study can be anticipated for further studies. This study only tested on one game, namely Mobile Legends: Bang Bang as the best-selling game in Indonesia. Further studies are expected to be able to test different contexts of mobile games and different environments. Furthermore, the samples in this study are dominated by male users. For further studies, it is recommended that gender equality be carried out in order to find better results.

\section{References}

Abdillah, W., \& Hartono, J. (2015). Partial Least Square: Alternatif Structural Equation Modeling (SEM) dalam Penelitian Bisnis Edisi 1. Yogyakarta: Penerbit ANDI.

Ajzen, I. (1991). The Theory of Planned Behavior. Organizational Behavior and Human Decision Processes, 50: 179-211.

Guo, Y. \& Barnes, S. (2007). Why People Buy Virtuals Items in Virtual Worlds with Real Money. ACM SIGMIS Database, 38(4): 69-76. 
Guo, Y. \& Barnes, S. (2009). Virtual Item Purchase Behavior in Virtual Worlds: An Exploratory Investigation. Electron Commer Res, 9: 77-96.

Guo, Y. \& Barnes, S. (2011). Purchase Behavior in Virtual World: An Empirical Investigation in Second Life. Information \& Management, 48: 303-312.

Guo, Y. \& Barnes, S. (2012). Explaining Purchasing Behavior Within Wolrd of Warcraft. Journal of Computer Information Systems, Spring, 18-30.

Hamari, J. (2015). Why Do People Buy Virtual Goods? Attitude Toward Virtual Good Purchases Versus Game Enjoyment. International Journal of Information Management, 35: 299-308.

Han, B. \& Windsor, J. (2013). An Investigation of the Smartphone User's in-Game Purchase Intention. International Journal Mobile Communications, 11(6): 617-635.

Hsu, C. L., \& Lu, H. P. (2007). Consumer Behavior in Online Game Communities: A motivational Factor Perspective. Computers in Human Behavior, 23(3): 1642-1659.

KumparanTECH. (2017). Di Indonesia, Mobile Legends Dimainkan 8 Juta Pengguna Aktif. Retrieved from https://kumparan.com/@kumparantech/di-indonesia-mobile-legends-dimainkan-8-juta-penggunaaktif.

Lehdovirta, V. (2009). Virtual Item Sales As A Revenue Model: Identifying Attributes that Drive Purchase Decisions. Electron Commer Res, 9: 97-113.

Lopez, M. (2017). On the Know: "Mobile Legends: Bang Bang”. Retrieved from https://criticalindex.net/ on-the-know-mobile-legends-bangbangf1f5a9c5d5ba.

Mäntymäki, M. \& Salo, J. (2013). Purchasing Behavior in Social Virtual Worlds: An Examination of Habbo Hotel. International Journal of Information Management, 33: 282-290.

Martín, H. S., \& Herrero, Á. (2012). Influence of The User's Psychological Factors on the Online Purchase Intention in Rural Tourism: Integrating innovativeness to the UTAUT framework. Tourism Management, 33, 341-350.

Sholihin, M., \& Ratmono, D. (2013). Analisis SEM-PLS dengan WarpPLS 3.0. Yogyakarta: Penerbit ANDI.

SuperData Research and Unity Technology. (2017). 2016 Mobile Games and Virtual Reality Review. Retrieved from https://www.superdataresearch.com/unity-and-superdata-launch-major-mobile-gamesand-vr-report/.

Venkatesh, V., Morris, G. M., Davis, B. G., \& Davis, D., F. (2003). User Acceptance of Information Technology: Toward A Unified View. MIS Quarterly, 27(3): 425-478.

Venkatesh, V., Thong, J., \& Xu, X. (2012). Consumer acceptance and use of information technology: Extending the unified theory of acceptance and use of technology. MIS Quarterly, 36(1): 157-178.

Wohn, D. Y., \& Na, E. K. (2012). Virtual Item Purchasing Patterns in a Social Game: Differences Between High and Low Spenders. In Proceedings of the 2012 iConference (431-432). Toronto, Ontario, Canada: ACM. 
Yee, N. (2006). Motivations For Play in Online Games. Cyberpsychology \& Behavior, 9(6): 772-775.

\section{Copyrights}

Copyright for this article is retained by the author(s), with first publication rights granted to the journal.

This is an open-access article distributed under the terms and conditions of the Creative Commons Attribution license (http://creativecommons.org/licenses/by/4.0/). 